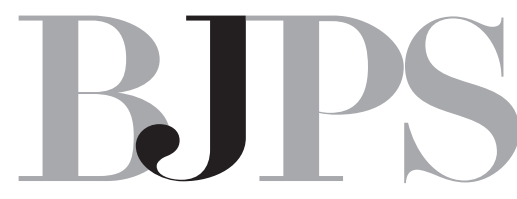

Brazilian Journal of

\title{
One year of BJPS!
}

One year has passed since complete reformulation of Revista Brasileira de Ciências Farmacêuticas was decided. Brazilian Journal of Pharmaceutical Sciences was born and since then the facts lead us to believe it succeeded.

One of the objectives of remodeling RBCF was to increase the international visibility of the Journal and, of course, of the Pharmaceutical Sciences that have been developed in Brazil, by assuming English as the official language.

Any modification almost always leads to complaints that arise from the difficulties in changing mentalities. Fortunately, we had a few. Only the first issue that can be considered as transition one was still published in English and in Portuguese. The others were completely launched in English, which has been reviewed by specialized professionals. The submission of foreign manuscripts to BJPS has increased and the tendency is to increase much more.

It is interesting to notice that manuscripts about pharmaceutical care and assistance have significantly increased, as a reflex of the direction of the Pharmaceutical Education from 2003 on that is committed with generalist pharmacist's graduation. This was observed also in RBCF, as mentioned in a previous Editorial, and we go on looking forward the increase in quality of those works.

Papers from all Pharmaceutical Sciences and related areas have been published, but those concerned to drugs and medicines, in all aspects, but mainly in Quality Control and Pharmaceutics, continue to be the most submitted and published. Probably this fact reflects the importance this area has assumed in the country. Notwithstanding, it is essential to emphasize that papers from other areas of Pharmaceutical Sciences are strongly welcome.

We are indebt with the authors for their comprehension with the changes in the journal, and for attention with the quality of their work. This has fundamentally contributed to the increase in the quality of BJPS.

The reviewers had a determinant role in this quality, since we could count on their seriousness, competence, and willing to evaluate the manuscripts. We are grateful for their relevant work. 


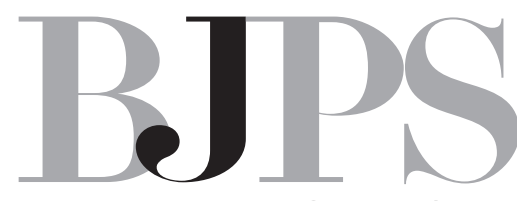

We are also grateful to the Publishing Committee and to the Executive Editor, Leila Aranha, whose outstanding efforts were determinant to make BJPS comes true. We extend our compliments to all member of BJPS Secretary.

FAPESP, CNPq, and the Support Program for Periodical and Scientific Publications of the University of São Paulo were fundamental to guarantee BJPS publication and distribution. Also, the subscribers have been very important not only for the interest in the Journal but also to their financial support.

It is worth to note that the celebration of the $70^{\text {th }}$ Anniversary of RBCF last November was attended by significant number of colleagues. Those who ever believed in the important role of the previous journal, RBCF, and those who realize the advance BJPS will represent in the near future celebrated together seven decades of the publication and the birth of its new and advanced generation. Professor Jorge Mancini Filho, the Dean of the Faculty of Pharmaceutical Sciences, fit both characters. Thanks to him and to Professor Hans Viertler, Dean of the Chemistry Institute, we also could celebrate, at the same event, the opening of the new Library building, which knowledge atmosphere must always be shared!

In the words of the Professor Suely Vilela, Magnificent Rector of USP, who gave high prestige to the celebration, we summarize the importance of the event:

"This commemoration is an additional gift that has been given to our Institution in its diamond jubilee. After all, count on a Journal that has been alive for decades, facing and overcoming challenges on behalf of an ideal, and attempted to change in order to grow up is a reason for the Institution's exultation".

Elizabeth Igne Ferreira

Scientific Editor 